\title{
Social Media Content - Coding Analysis of Sexual Assault Allegations
}

\author{
Terri Juneau \\ Texas Woman's University \\ USA
}

\begin{abstract}
The purpose of this study is to examine news stories on two popular social media platforms - Facebook and Twitter and see what attributions are made regarding alleged female sexual assault victims via the online comments section. This study will look at three prominent male alleged offenders in Harvey Weinstein, Bill Cosby and Brett Kavanaugh and compare comments on both Facebook and Twitter on three different news stories by The Washington Post involving their alleged victims. Using a completely qualitative coding analysis and descriptive statistics, this study will examine whether labeling theory and stigma play a role in these attributions and also explore further conditions that might influence a person's ideas of the alleged victim and if power, prestige and authority play a role in how the public views alleged sexual allegations.
\end{abstract}

\section{Introduction}

When it comes to sexual assault allegations, are there some victims whose claims hold more validity to an online audience? Are there some alleged perpetrators that are viewed differently by social media even though the allegations may be the same as another who is vilified? These are the questions that can only be answered if we venture out into the potential quagmire of social media comments. The thought process behind this study is that the ascriptions made by social media commentary support to aid labeling theory and stigmas, which in turn can be used as weapons against alleged victims or as cause célèbre by alleged culpritsin some cases. It also looks at the dogma that males with power, prestige and authority may have less blame in the eye of the public, have less punishment or no punishment at all when compared to similar acts performed by other males and may themselves become an "ideal perpetrator". By decoding who these commenters are and factors that might influence opinions of alleged victims, this study hopes to paint a better picture of what exactly can be gleaned from studying posts and tweets in an online forum. Because the study is completely qualitative, open coding will be used to look for emerging themes to help narrow down codes tied to three of the most recent and prevalent cases involving alleged sexual assault - Harvey Weinstein, Bill Cosby and Brett Kavanaugh.

\section{Literature Review}

\section{Social Media in General}

Few would argue against the fact that social media is a powerful tool, bringing together people from all over the world and creating an idea of "safe spaces" to share one's own ideology. Due to the vast number of subscribers to these platforms, data can travel at a faster rate than ever imagined, helping people understand what is happening in the world by providing real time information all at the click of a button. Social media is also a perfect medium for bringing together people of similar thought and helping to solidify unity. We see how social media can be a "stitching" (Hemsley, Jacobson, Gruzd, \& Mai, 2018) mechanism, bringing together technology and people and creating popular movements. If we look at prevalent hashtag campaigns over the past two years - such as \#MeToo, \#Timesup and \#AintNoCinderella - we can directly trace the origins of these revolutions through their birth from social media platforms to now becoming part of our everyday culture and vernacular. Marches, protests and boycotts have all been undertaken in the name of these social movements that arise when social media unites technology with people. Alongside this, however, there is another issue that many researchers have yet to fully investigate: There are very few studies that look at and study the comments section of social media, especially within the realm of sociology. In order to fully understand these commenters" opinions, the "who" and "why" of these posters should first be examined.

\section{The Who and the Why}

Understanding this invisible audience of social media users is a must for any researcher looking to text mine, data mine or qualitatively code a relatively large group of information. There are researchers who have tried applying McCrae and Costa's Five-Factor Model of personality towards online commenting behavior (Barnes, Mahar, Wong, \& Rune, 2017). The Five-Factor Model contemplates a person's extraversion, agreeableness, conscientiousness, neuroticism, and openness to experience(McCrae \& John, 1992) and when applied to online commenting behavior can provide some 
insight as to those who are most likely to leave thoughts online, as these five traits held steady over a person's lifetime in most cases.

It was found that introverts, rather than extroverts, were most likely to take to commenting online (Hamburger \& BenArtzi, 2000), as extroverts tended to post aspects of their daily life online but preferred face to face interactions as a whole. The spiral to this aspect happens when looking at which platform type we look at: Introverts comment more online, but they do so only in a social media space that allows for ambiguity of self or anonymous posting, whereas extroverts prefer to post on social media sites that allow them to fully expose who they are (Barnes et al., 2017). For the purposes of this study, we will be using the latter, so with that in mind, we can expect to see extroverted citizens posting their attributions. Neurotics, or people who are not emotionally stable, tend to post more comments as they are seeking not only social support but also are seeking positive feedback from likeminded individuals (Correa, Hinsley, \& de Zúñiga, 2010)as this enables them to feel like they are not only correct in their attributions but also not alone in their assumptions. This makes full sense as people who are neurotic tend to be very insecure in themselves and would want to find an audience that reinforces their own beliefs. Being open to new experiences also has a high correlation with whether or not someone will post a comment as research shows a high correlation to information seekers being online commenters (Correa et al., 2010). As far as agreeableness andconscientiousness go, there is no data that has found significant indications regarding the two traits when linked to online usage or online commenting. When synthesizing this information, a clearer picture emerges of people who will be making these attributions: Neurotic, extroverted and open to experiences (Barnes et al., 2017). This study also bears in mind the golden rule of online reviews, which applies as well to social media comments: People who review or comment in online social media forums are almost always either very angry or very happy. Few people who are indifferent take the time required to post a review or make a comment. This is also expected to hold true with comments sections.

\section{Conditions that influence comments}

Now that the "who" and "why" of social media commenters have been examined, this study will take a look into possible external factors that would influence a person's attributions of the articles to be researched.

\section{Bias}

The first condition to address would be bias, both personal and media-based. Bias, simply put, is one's own prejudice, favoritism or inclination to one side or another. When looking at social media user's attributions on particular articles, a researcher has to know that bias will be involved on not only a personal level, but also on a media level as well. People read news articles without often consciously considering if there is an inclination towards a particular party or outcome. Most people do not think of the media, especially the news, as being a place of bias, yet recent research has indicated this to be completely untrue (Elejalde, Ferres, \& Herder, 2018) and confirms what we are now seeing with labels such as "fake news" or "alt-right news": The media, especially news, is heavily biased. A story released on Breitbart, Infowars or FOX News, for example, which all lean heavily towards a conservative Republican audience, will not read the same way when posted on MSNBC, Huffington Post or Occupy Progressives. To show a better picture of bias in 
media, included is a chart of news outlets and where they tend to fall interms of bias (Otero, 2017).

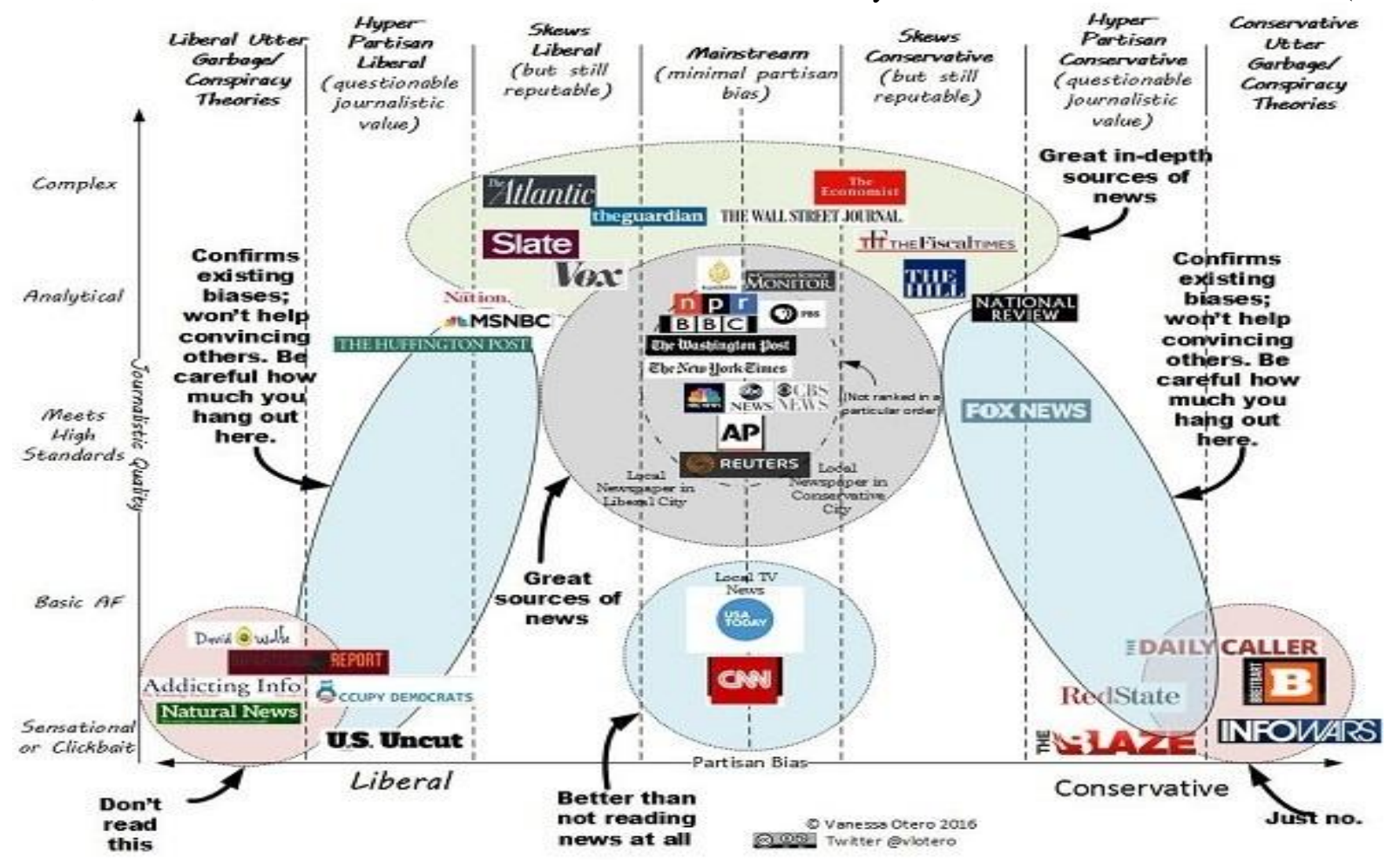

(Used with permission by author.)

This chart will assist in illustrating why only articles published by two sources that are found in the very middle were chosen for review; this will be discussed further in methodology. The news is hypothetically supposed to inform in a neutral manner, yet many Americans are getting their news from sources that have a political agenda. New research is being done to point out that prejudice doesnot just lie within our own persons, but also within places (Murphy, Kroeper, \& Ozier, 2018). While typically we would define place as a tangible item, in this instance we can see that online news communities that adhere to a certain ideology or political leaning can be interpreted as a place that shows prejudice. Research communities and the scientific world are constantly calling out the media for sensationalizing and showing very little signs of journalistic objectivity (Praveen Kumar, 2016) yet this has not abated the stories. Naturally, one would assume that if a person is getting their news from a place such as Breitbart, a source generally quite favorable to President Trump, their attributions regarding a sexual allegation against Trump will more than likely slant towards a predisposition of rejecting the accuser, which is why it is important for this study to include this factor. Social identity theory proposes that similar people want their news from a source much like themselves and that if news comes from a network that is not in line with their allegiances, they will reject it (Gunther, McLaughlin, Gotlieb, \& Wise, 2017), which is why it is so important to take this into account when looking at comments. One cannot just look at a comment without looking at the source.

\section{False Allegations and Ambiguous Definitions}

Another factor considered is the idea of false allegations and ambiguous definitions. There is a common misconception among Americans, especially male, that women "cry rape" and therefore the idea that there are thousands of cases against men that are false. However, the research conducted on false allegations over the years points to the opposite: Most research shows that the ate of false allegations when tied to sexual assault is between 2 to 10 percent (Lisak, Gardinier, Nicksa, \& Cote, 2010). Due to the hostile political climate and given the fact that it is emotionally charged, these claims of false allegations when tied to sexual assault have no scientific or quantifiable backing that could be found. It is also worth noting that as a society, we have yet to come up with definitions of rape, sexual violence and sexual assault that everyone can agree on, which further hinders how cases are handled, and that in and of itself could be the reason for some of the 2 to 10 percent of these types of cases as being labeled "false allegations." An international case that had many Americans trying to decipher what exactly constitutes rape, sexual violence or sexual assault was the alleged allegations against WikiLeaks founder Julian Assange, who stands accused of having raped a woman by pinning her down and refusing to wear a condom (among other allegations). 
Due to the reporting that she had consensual sex with him once and that many other allegations were not reported, many Americans were confused as to why he was charged with rape. In this case it is apparent that the news media controls what the narrative is to its intended audience (Harrington, 2018). A case that shows the ambiguity of rape and of consent when it comes to laws would be that of Abigail Finney at Perdue University in 2017, when she fell asleep with her boyfriend in his dorm room, only to be awoken by him fondling her breast. She was facing away from him and reached back and inserted his penis inside of her. After hurried sex, she turned around to find it was a friend of her boyfriend, not him, that she had had sex with. This case made news because in the state of Indiana what happened to her was not rape because it was not obtained through force, threats and she was aware she was having sex. It just was not with the man she thought it was. According to the recent laws on consent by RAINN (Rape, Abuse \& Incest National Network) more than three quarters of US states and territories do not have definitive laws regarding consent, which makes understanding rape that more ambiguous.

\section{Rape Culture}

In addition to these factors, one must take into account that we live in a space in which rape culture exists. Rape culture's working definition would be we live in a society that normalizes sexual violence towards women (Nagy, 2018). It is prevalent in a variety of entertainment mediums. We have multi-national "SlutWalks" in response to a constable telling women to "stop dressing like sluts so you won't be victimized." Slutwalk organizers called for an end to rape culture and victim blaming. (McCormack \& Prostran, 2012)Rape culture is widespread in our sports teams, with many celebrity athletes committing sexual assault or intimate partner violence.Pittsburgh Steelers quarterback Ben Roethlisberger was accused by two different women of rape, with one case being handled out of court and the other, with three witnesses confirming the rape charge, being declined by the district attorney.Baylor is a textbook example of the perpetuation of rape culture on a college campus, having just settled a Title IX lawsuit that accused no less than eight former Baylor football players of gang rape.Donald Trumpbecame the $45^{\text {th }}$ President even after being quoted as saying that because he was a star, he could do anything he would like to women, even if that meant "grabbing them by their pussy." This quote led to widespread talk about what was considered "locker room talk" and then started its own hashtag in the \#NotOkay movement (Maas, McCauley, Bonomi, \& Leija, 2018). As seen in the cases above, the hypothesis that males in a position of prestige and/or power face less consequences or sometimes none at all holds true, as well as the ideology that they share less blame when compared to other males who commit the same crimes without the prestige.

\section{\#Hashtag Activism}

We cannot talk about rape culture without giving some credence to the \#MeToo movement, initially started by Tarana Burke in 2006 but which gained widespread notoriety in 2017 when Alyssa Milano tweeted it. Hashtag activism is now a growing field thanks to social media, but it is unknown how much it will do for social change until much later (Mendes, Ringrose, \& Keller, 2018). Several other hashtag campaigns have spun off from \#MeToo, with \#WhyIStayed, \#BeenRapedNeverReported and \#IStandWithHer (which was unique to the Brett Kavanaugh hearings with regard to Christine Blasey Ford, his accuser) being a few of the predominant ones. These challenges to rape culture are quantifiable if we are talking posts and tweets, but whether or not they will actually cause a shift is still inconclusive. The reason hashtag activism was used as a factor that could influence attribution is because there continues to be a lot of criticism regarding these movements in regards to only highlighting the plight of white women while leaving minorities behind (Slakoff \& Brennan, 2017). After all, \#MeToo was conceived as a way for African-American women to highlight their struggle, but very little attention was paid to it until a prominent white female used it (or, as some would argue, co-opted it). This raises issues for some Americans as to who is able to speak out (as many impoverished and minority women cannot) and who these hashtags are really for (Zarkov \& Davis, 2018). In a recent Spiderman crossover movie that is in the works ("Spider-Woman"), Deadline's Mike Fleming Jr. mentions the movement as a reason for the movie (Fleming, ), which leads to a lot of questions about the future of \#MeToo and hashtag activism being linked to commercialization of victimization. Neil DeGrasse Tyson, recently levied with sexual allegation charges, just posted a lengthy statement on his Facebook wall in which he calls out hashtag activism for letting emotions outweigh evidence and for holding a court not in a courtroom but in the court of public opinion. Comments on this post shows just how far \#Metoo is being vilified by men.

\section{Labeling Theory and Stigma}

Considering all of these factors above, it is not hard to see why certain people would make certain assumptions and attributions of sexual assault accusers. There are reasons that people focus on what the accuser wore, if she was drinking, or if she went back to his place. The Rape Myth Acceptance (RMA) in our society is remarkably high, with most people believing that most rapes occur by strangers, (Ayala, Kotary, \& Hetz, 2018) even though $80 \%$ to $90 \%$ of rapes occur by perpetrators that the victim knows. 
Due to this myth, knowing the perpetrator makes it less likely to be reported by the victim because they do not consider it rape. More blame attribution was put upon victims of acquaintance rape than of those who were raped by strangers in research because people believe that women who know the assailant should have foreseen the attack (Perrott \& Webber, 1996). When as a society refuses to support a victim a stigma effect occurs almost as a what researcher has described as a "second injury" (Symonds, 2010) as they feel a second assault by not being believed or being questioned about their role in the attack. Women in the cases of Weinstein, Cosby and Kavanaugh were asked questions about what they were wearing, why they would go up to a hotel room alone, why they went to a party and all of these questions add to the second injury of victimization which in turn leads to stigma and labeling. Sexual assault is predominantly stigmatizing due to the common place of negative feedback incurred when a victim discloses what has happened. Even when positive feedback is also given it is not taken and internalized with the same weight of that of negative comments or attributions. This social negativity hypothesis (Ullman \& Najdowski, 2011)leads many victims unwilling to disclose to others what occurred. With this hypothesis negative comments, whether it be in person or online, reinforces that they were somehow at fault for the assault and leads to victims agreeing to the negative feedback given by society.

There are other reasons that society places blame on certain victims but not on others. In the mid-1980s sociologist and criminologist Nils Christie came up with what he referred to as the "ideal victim" and claimed that in order for a victim to be deemed innocent or worthy in a social response, they would need to adhere to five key attributes in order to gain empathy and support (Christie, 1986). They would need to be viewed as (1) defenseless or weak, (2) be engaging in behavior that is deemed well-thought-ofat the time they were victimized, (3) absolutely blameless in the situation that caused the offense, (4) have the attacker be viewed as an insidious offender that they (5) did not know. Recent research has found that if the victim of sexual assault is in a relationship or knows their perpetrator, thus not fulfilling the fifth attribute Christie puts forth, the blame lies more on the victim and less on the victimizer. (Meyer, 2016) People believe that if the victim knew the attacker and was being abused, they should have simply left the relationship or tell the person no. This also creates stigma for women who are trying to get out of abusive relationships, as society deems women being abused by boyfriends, husbands and significant others as sharing blame in the offense by not leaving the situation. In interpersonal relationships of violence victim-blaming is much higher than in stranger violence and the idea of being stigmatized leads many women to not report sexual violence or assault (Meyer, 2016). In a college student study, factors were examined to see why they had certain judgements and negative attributions on different hypothetical rape victims. They gave victim blaming feedback on scenarios in which the female victim was wearing inappropriate clothing, if she had been drinking alcohol, if she had been flirting with the assailant and if she knew the offender (Ullman, 1996). These attributes all go against the "ideal victim" characteristics, so these hypothetical victims were stigmatized and labeled as either lying about the rape or provoking it. Keeping in mind that this was a study that used hypothetical situations, this study expects to find that the same negative attribution mechanism at work above will be prevalent in real life cases that are looked at.

It also matters when it comes to authority. The reason that this study chose the three alleged perpetrators were due to their role as an authority figure towards the alleged accuser. In a recent study of young women ages 15-19, 1 in 5 said they were forced into sex acts by males who used their position of authority to sexually assault them (Morrison-Beedy \& Grove, 2018). In the case of Harvey Weinstein, he used his role as the founder of Miramax to allegedly sexually assault many female actresses and exploited his role for sexual gain. In the case of Bill Cosby, his accusers were typically fans or up and coming actresses that viewed him as an admired actor and trustworthy person, yet he used promises of movie and television roles to lure women into a sense of security before allegedly drugging and then raping them. While Brett Kavanaugh may have not been in a place of authority at the time of his allegations, he most certainly was in such a spot when those allegations finally came out. Many would argue that being the nominee for Donald Trump's Supreme Court Justice position had Kavanaugh in a position to not only silence possible victims but to discredit or create stigma to those victims who did come forth.In all of these cases, this study has seen that online shaming of the victim(s) typically occurred if the person doing the shaming felt the victim did not meet one of Christie's five attributes of ideal victims or if social identity theory was in play and they rejected the allegation because it did not line up with their own beliefs. Social shaming is not relegated to one's actions but to the actual character of the person (Barrett, 2017) as seen in the comments section of most of the news stories the study chose. "You are a whore" and "you are too ugly to get raped" are common among all of these stories, calling out the alleged victim's character and not the actions.

When looking at the "ideal perpetrator" hypothesis, this study finds that had these men not been in positions of prestige or authority they would not only face more social blame but would also face more criminal punishment. The ideal perpetrator label holds the most weight with Brett Kavanaugh, with many people believing that because of his age at the time of the offense he was simply doing what any normal college male would do if intoxicated. 
Positive attributions such as graduating with honors from Yale University and then Yale Law, clerking for Ken Starr and Anthony Kennedy, having a successful law practice and what many believe a "family man" demeanor all aid in the ideal perpetrator scenario. Unlike that of Weinstein and Cosby, his allegations were segregated to one specific time in his life, with many believing that this factor sets him completely apart from all other alleged offenders. The President defended Kavanaugh and made statements implying that had such assaults taken place the alleged victims would have simply reported them at that time. Excluding the ideal victim of Christine Blasey Ford, many attributions made by society many of the alleged victims became stigmatized and labeled as whores, gold diggers and liars.

\section{Methodology}

\section{Data Retrieval}

Due to the sharing of public data on both Facebook and Twitter and the absence of interaction between the researcher and participant, a waiver by the University's review board should be granted. After the approval of that waiver, data from the following three articles and comments will be collected and preserved from page inception through December $1^{\text {st }}, 2018$ on both social media platforms used in this study (Facebook and Twitter). This study will be using "The rise and ignominious fall of Harvey Weinstein, in four acts" (Eltagouri Marwa, Rosenberg Eli, \& Hui Mary, 2018), "Bill Cosby's publicist likens fallen actor to Jesus as he decries 'sex war' also engulfing Kavanaugh" (Stanley-Becker Isaac, 2018) and "The rise and the reckoning: Inside Brett Kavanaugh's circles of influence" (Fisher Marc, Marimow Ann, \& Kranish Michael, 2018) as its source for comments, as both stories appear in both social media platforms. Comments will not include reposts nor retweets and $n=550$, with Facebook $n=452$ and Twitter $n=98$.

\section{Procedures}

Generally speaking, most experts find reliable coding for text an impossible task, or one that is far too subjective to produce factual results (Lombard, Snyder-Duch, \& Bracken, 2002). In order to produce the highest level of reliability and safeguard systematic information analysis, the researcher will take steps suggested such as dissection of text, codebook construction, coding, assessing validity and reliability of codes, codebook amendments, and then create final codes, and throughout all processes reiterating steps to produce accuracy (Hruschka et al., 2004). The researcher will need to read each comment independently and then use dissection of text to comprise codes from emerging trends. After those codes are agreed upon the researcher can then create a codebook in which gender, race and age are included, as well as residency on a state level. In order to maintain subjectivity, another researcher should be added to code using the codebook guidelines after the initial researcher has completed and then those results should be compared for accuracy(Linker, Valley, O' Connor, \& Newman Daum, 2018). This process should be done multiple times and modifications made if any ambiguity or discourse about codes or the codebook arise between the researchers.

\section{Expected Results}

This study expects to find high levels of victim blaming when looking at women who do not fit the Christie "ideal victim" characteristics, such as Rose McGowan or Janice Dickinson, as McGowan took money from Harvey Weinstein to allegedly keep silent about rape and Janice Dickinson has a history of making allegations against celebrities and is viewed by many as a "media whore" who loves attention. It also expects to find that when an accuser has had any character blemishes such as arrests, drug problems or is viewed as having something to gain, people will either dismiss the allegations or question validity. The study also expects to find a correlation with gender and validity of allegations, with males believing in RMA or false allegations more than women, Race could also play an important role in looking at Cosby, with expectations that African Americans reject allegations made against him. When looking at Kavanaugh, the study expects that race and gender will couple with region, as states that vote republican justifying his behavior as "boys will be boys" by men and white republican males feeling the most solidarity with him and rejecting allegations even when an "ideal victim" like Christine Blasey Ford is presented. This study believes that instead of an "ideal victim" in these cases an "ideal perpetrator" might arise when looking at Kavanaugh as he does not fit or look the part and his allegations are very debatable as to the exact definition of rape and sexual assault. The researcher also expects to find high levels of empathy for Ford as she fits the "ideal victim" mold as well as some level of empathy for Cosby due to his age and disabilities, with many rationalizing that he is not a threat to reoffend and should be set free. High levels of doubt and questioning of statue of limitations (why didn't accusers come forth before?) in all cases is expected, with positive attributions made by social media commenters divided on Kavanaugh's accusers but more negative on certain accusers in both Weinstein and Cosby's cases. 


\section{Conclusions}

When dealing with social media there are certain limitations that the research runs into. One cannot be sure that the gender, race, age or region of the commenter is correct, as many people put fake profiles on both of the social platforms. Another issue to consider is if the commenter is being honest with their attributions and assumptions or if they are merely "trolling", trying to start discourse or manipulate the narrative. Social media data mining is still in its infancy, so many researchers do not see value in it and prefer face to face interviews or focus groups due to the fact that a social media analysis might miss subtle or unspoken descriptions. With this particular study the sample size is relatively small, but in order to conduct a realistic proposal a sample size cannot be too large. The articles all come from one source so in the future comments should come from a multitude of sources that fall within the boundaries of little bias, but also comments should be mined from different social platforms as technology is a constantly growing and changing. This paper only takes into account U.S. policies and social commentary and it excludes those who do not have access to social media. Social media research also runs into an issue with consent. Should researchers ask for permission to use "cyber people" or simply call the comments posted by them as public information? One would assume making comments on platforms where you can make your account/profile private would constitute consent, but further research needs to be done in this area.

\section{Acknowledgements}

The author would like to thank Mrs. Vanessa Otero and Ad Fontes Media, Inc. for permission to use the media bias chart on page 6.

\section{References}

Ayala, E. E., Kotary, B., \& Hetz, M. (2018). Blame attributions of victims and perpetrators: Effects of victim gender, perpetrator gender, and relationship.Journal of Interpersonal Violence, 33(1), 94-116. doi:10.1177/0886260515599160

Barnes, R., Mahar, D., Wong, I., \& Rune, K. (2017). A neurotic extrovert who is open to new experiences? understanding how personality traits may impact the commenting behaviors of online news readers. Journal of Broadcasting \& Electronic Media, 61(3), 557-573. doi:10.1080/08838151.2017.1344671

Barrett, E. C. (2017). SOCIAL SHAMING: Professor's research explores online actions. Human Ecology, 45(2), 12.

Christie, N. (1986). The ideal victim. From Crime Policy to Victim Policy,

Correa, T., Hinsley, A. W., \& de Zúñiga, H. G. (2010). Who interacts on the web?: The intersection of users' personality and social media use doi://doi.org/10.1016/j.chb.2009.09.003

Elejalde, E., Ferres, L., \& Herder, E. (2018). On the nature of real and perceived bias in the mainstream media. PLoS ONE, 13(3), 1-28. doi:10.1371/journal.pone.0193765

Eltagouri Marwa, Rosenberg Eli \& Hui Mary. (2018). The Rise and Ignominious Fall of HarveyWeinstein, in Four Acts. Retrieved fromhttps://www.facebook.com/washingtonpost/posts/10157767579542293

Fisher Marc, Marimow Ann, E. \& Kranish Michael. (2018). The rise and the reckoning: Inside BrettKavanaugh's circles of influence. Retrieved from https://www.facebook.com/washingtonpost/posts/10158163958807293

Fleming, M.Sony builds out spider-man universe with A spider-women film. November 27, 2018, Retrieved from https://deadline.com/2018/11/spiderwoman-movie-spiderman-sony-pictures-bek-smith-amy-pascal$1202509718 /$

Gunther, A. C., McLaughlin, B., Gotlieb, M. R., \& Wise, D. (2017). Who says what to whom: Content versus source in the hostile media effect. International Journal of Public Opinion Research, 29(3), 363-383. doi:10.1093/ijpor/edw009

Hamburger, Y. A., \& Ben-Artzi, E. (2000). The relationship between extraversion and neuroticism and the different uses of the internet doi://doi.org/10.1016/S0747-5632(00)00017-0

Harrington, C. (2018). Feminist killjoys and women scorned: An analysis of news and commentary on the sexual violence allegations against JulianAssange. Feminist Criminology, 13(1), 87-111. doi:10.1177/1557085116646194

Hemsley, J., Jacobson, J., Gruzd, A., \& Mai, P. (2018). Social media for social good or evil: An introduction. Social Media + Society, 4(3), 2056305118786719.doi:10.1177/2056305118786719

Hruschka, D. J., Schwartz, D., St. John, D. C., Picone-Decaro, E., Jenkins, R. A., \& Carey, J. W. (2004). Reliability in coding open-ended data: Lessons learned from HIV behavioral research. Field Methods, 16(3), 307-331. doi:10.1177/1525822X04266540 
Linker, J. M., Valley, J. A., O' Connor, J. A., \& Newman Daum, D. (2018). Physical education gym class heroes, tryhards, and all-stars: An analysis of Facebook comments. Physical Educator, 75(3), 414-437. doi:10.18666/TPE-2018-V75-I3-7882

Lisak, D., Gardinier, L., Nicksa, S. C., \& Cote, A. M. (2010). False allegations of sexual assault: An analysis of ten years of reported cases. Violence Against Women, 16(12), 1318-1334. doi:10.1177/1077801210387747

Lombard, M., Snyder-Duch, J., \& Bracken, C. C. (2002). Content analysis in mass communication: Assessment and reporting of intercoder reliability. Human Communication Research, 28(4), 587-604. doi:10.1111/j.14682958.2002.tb00826.x

Maas, M. K., McCauley, H. L., Bonomi, A. E., \& Leija, S. G. (2018). "I was grabbed by my pussy and its \#NotOkay": A twitter backlash against DonaldTrump's degrading commentary. Violence Against Women, 24(14), 17391750. doi:10.1177/1077801217743340

McCormack, C., \& Prostran, N. (2012). Asking for it. International Feminist Journal of Politics, 14(3), 410-414. doi:10.1080/14616742.2012.699777

McCrae, R. R., \& John, O. P. (1992). An introduction to the five-factor model and its

applications. Journal of Personality, 60(2), 175-215.

Mendes, K., Ringrose, J., \& Keller, J. (2018). \#MeToo and the promise and pitfalls of challenging rape culture through digital feminist activism. European Journal of Women's Studies, 25(2), 236-246. doi: $10.1177 / 1350506818765318$

Meyer, S. (2016). Still blaming the victim of intimate partner violence? women's narratives of victim desistance and redemption when seeking support. Theoretical Criminology, 20(1), 75-90. doi:10.1177/1362480615585399

Morrison-Beedy, D., \& Grove, L. (2018). Adolescent girls' experiences with sexual pressure, coercion, and victimization: \#MeToo. Worldviews on Evidence-Based Nursing, 15(3), 225-229. doi:10.1111/wvn.12293

Murphy, M. C., Kroeper, K. M., \& Ozier, E. M. (2018). Prejudiced places: How contexts shape inequality and how policy can change them. Policy Insights from the Behavioral and Brain Sciences, 5(1), 66-74. doi:10.1177/2372732217748671

Nagy, V. (2018). Nickie D Phillips, Behind blurred lines: Rape culture in popular media. Australian \& New Zealand Journal of Criminology, 0004865818805608. doi:10.1177/0004865818805608

Otero, V. (2017). Media bias chart Retrieved from https://www.adfontesmedia.com/news-quality/

Perrott, S. B., \& Webber, N. (1996). Attitudes toward male and female victims of sexual assault. Journal of Psychology \& Human Sexuality, 8(4), 19-38. doi:10.1300/J056v08n04_02

Praveen Kumar, N. (2016). Journalistic objectivity in media risk debates: Challenges \& opportunities. Clarion: International Multidisciplinary Journal, 5(1), 91-97. doi:10.5958/2277-937X.2016.00013.7

Slakoff, D. C., \& Brennan, P. K. (2017). The differential representation of Latina and Black female victims in frontpage news stories: A qualitative document analysis. Feminist Criminology, , 1557085117747031. doi:10.1177/1557085117747031

Stanley-Becker Isaac. (2018). Bill Cosby's publicist likens fallen actor to Jesus as he decries 'sex war' also engulfing Kavanaugh. Retrieved from https://www.facebook.com/washingtonpost/posts/10158143064972293

Symonds, M. (2010). The "second injury" to victims of violent acts. 1980. American Journal of Psychoanalysis, 70(1), 34-41. doi:10.1057/ajp.2009.38

Ullman, S. E. (1996). Social reactions, coping strategies, and self-blame attributions in adjustment to sexual assault. Psychology of Women Quarterly, 20(4), 505-526. doi:10.1111/j.1471-6402.1996.tb00319.x

Ullman, S. E., \& Najdowski, C. J. (2011). Prospective changes in attributions of self-blame and social reactions to women's disclosures of adult sexual assault. Journal of Interpersonal Violence, 26(10), 1934-1962. doi:10.1177/0886260510372940

Zarkov, D., \& Davis, K. (2018). Ambiguities and dilemmas around \#MeToo: \#ForHow long and \#WhereTo? European Journal of Women's Studies, 25(1) 